\title{
How to Optimize the Management of Science and Technology Funds in Colleges and Universities Based on the Policy of Streamlining Administration, Delegating Powers, Improving Regulation, and Strengthening Services
}

\author{
Rongli Zhou*, Jie Ji \\ Dalian Jiaotong University, Dalian 116028, Liaoning Province, China
}

\begin{abstract}
To advance the field of science and technology, we need to revitalize the development of science and technology through innovation. The development of science and technology has many beneficial implications on the revitalization of the country. For this reason, universities in China should give full attention to their role as the main propeller of science and technology. "Streamlining administration, delegating powers, improving regulation, and strengthening services" is a policy issued by the Chinese government for the management of science and technology funds in colleges and universities. Based on the policy of "streamlining administration, delegating powers, improving regulation, and strengthening services," colleges and universities must optimize the management of science and technology funds for their efficient use. In this paper, we analyzed the importance of the policy and put forward an effective management strategy, aiming to improve the management of science and technology funds in colleges and universities.
\end{abstract}

Keywords: Streamlining administration, delegating powers, improving regulation, and strengthening services; Colleges and universities; Funding for science and technology; Management strategy

Publication date: May, 2021; Publication online: 31 May, 2021

*Corresponding author: Rongli Zhou, rongliaaa@163.com

\section{Introduction}

In conjunction with the continuous development of science and technology, colleges and universities need to take on the important tasks of revitalizing the country through science and technology, and of completing scientific research as a key task. The funding for science and technology in colleges and universities continues to grow. Thus, the Chinese government has issued a series of related policies and procedures for the management of science and technology funding in colleges and universities, putting forward an important measure of "streamlining administration, delegating powers, improving regulation, and strengthening services." In the process of managing these funds, colleges and universities must recognize the importance as well as explore the policy of "streamlining administration, delegating powers, improving regulation, and strengthening services" for the development and efficiency of this work.

2 Importance of "Streamlining Administration, Delegating Powers, Improving Regulation, and Strengthening Services" to the Management of Science and Technology Funds in Colleges and Universities

Universities play a major role in the field of science and technology, and relevant departments attach great importance to the management of science and technology funds in universities. After the implementation of the policy of "streamlining administration, delegating powers, improving 
regulation, and strengthening services," new requirements have been put forward for the management of science and technology funds in universities. The main content of the policy of "streamlining administration, delegating powers, improving regulation, and strengthening services" is shown in Table 1.

Table 1. Main content of the policy of "streamlining administration, delegating powers, improving regulation, and strengthening services"

\begin{tabular}{ll}
\hline Policy & Specific contents \\
\hline Streamlining administration & Streamline administrative powers and decentralize powers to \\
expand the management of science and technology funds in \\
universities. The power of decentralization mainly includes \\
the right to autonomously manage travel expenses and \\
conference fees, and the right to independently purchase \\
research equipment.
\end{tabular}

Delegating powers, and improving Standardized management.

regulation

(1) Develop a detailed internal management plan based on the actual situation of science and technology funding in the universities.

(2) Implement science and technology fund management in accordance with relevant laws, regulations, and system specifications, and strengthen the assessment of funding management.

(3) Internally openly manage science and technology expenditures and strictly supervise science and technology expenditures.

Strengthening services

Optimize service. Simplify the management process of science and technology funds in universities, and do not implement inspections when unnecessary, to reduce the burden on scientific research personnel. Through the combination of loosening and incentive measures, the innovation and creativity of researchers can be stimulated.

Under the policy of "streamlining administration, delegating powers, improving regulation, and strengthening services," the reform of science and technology fund management in the university has been steadily advanced. In the new vibrant environment, the innovative ability of scientific researchers has become even higher. When the older version of science and technology fund management system was in place, the innovation enthusiasm of researchers were generally diminished. The implementation of the policy of "streamlining administration, delegating powers, improving regulation, and strengthening services" has just solved this problem. It not only standardizes the management process of university science and technology funds, but also streamlines administration and decentralization, improving the management of science and technology funds in universities in accordance with the policy. Nonresearchers have created a good environment, where the use of scientific and technology funds have become more reasonable. Under such a condition, researchers can devote themselves more to research and teaching. 
3 Effective Strategies for the Management of Science and Technology Funds in Colleges and Universities Based on the Policy of "Streamlining Administration, Delegating Powers, Improving Regulation, and Strengthening Services"

\subsection{Full service for research activities}

Based on the policy of "streamlining administration, delegating powers, improving regulation, and strengthening services," universities should actively implement a technology financial assistant system to provide better services for research personnel, encourage financial personnel to participate in research and fine-tune budgeting in the early stage of the research. In the process of research, the reimbursement of funds, project acceptance and conclusion of the project in the later stage of scientific research should be optimized. This will not only improve the uniformity and rationality of university's science and technology fund management, but also encourage researchers to devote their time to research.

Furthermore, it is important to publicize the research policies that encourage researchers to abide by the laws and regulations of our country. Universities can use network information platforms, such as WeChat official accounts, QQ groups, etc., to publicize relevant laws and regulations, and policies of science and technology fund management. Financial knowledge should be popularized among scientific researchers so that they are aware that science and technology funds are not the personal property of a certain individual. The expenditure of funds needs to be consistent with the scientific research direction of the project. The person in charge of the project needs to ensure the authenticity of each expenditure and expands the use of funds while improving the management level of science and technology expenditures.

\subsection{Building a science and technology fund management system using information technology}

In the process of implementing science and technology fund management, colleges and universities should understand and discern the impact of information technology on the management of science and technology funds ${ }^{[1]}$ and attach importance to the use of information technology to build a science and technology fund management system for colleges and universities. The departments involved mainly include research departments, finance departments, and human resources management departments. The establishment of the management system can not only solve the problems between these departments in the past, such as working independently, performing only their own work, and lacking a comprehensive understanding of the situation of research projects, but also strengthening the communication and information sharing between various departments, thus effectively improve the management level of science and technology funds in universities. In the past, researchers needed to submit relevant materials to multiple departments in the process of research, which not only wasted the time of researchers, but also affected the research personnel who should fully focus on their research and teaching. The establishment of the management system has realized information sharing and simplified various procedures. In addition, colleges and universities should also increase the application of advanced "big data" technology and "Internet +" technologies, and transfer science and technology fund management tasks, such as the submission of materials and online appointment for reimbursement, to the network platform ${ }^{[2]}$.

\subsection{Strengthening the supervision of the} management of science and technology funds

Under the policy of "streamlining administration, delegating powers, improving regulation, and strengthening services," if universities want to ensure the rationality and scientificity of science and technology fund management, they must pay attention to strengthening the supervision of the management of science and technology funds, avoiding the phenomenon of abuse of power within colleges and universities, and reducing the risks as much as possible while regulating power before, 
during and after the use of the funds (Table 2) ${ }^{[3]}$.

\subsection{Strengthening incentives for research personnel}

Talents are the key force for science and technology innovation. For this reason, while managing science and technology funds in the colleges and universities based on the policy of "streamlining administration, delegating powers, improving regulation, and strengthening services," it is important to strengthen the incentives for research personnel, so as to enhance the enthusiasm of research personnel for science and technology innovation (Table 3$)^{[4]}$.

Table 2. Supervision of the management of science and technology funds

\section{Supervision of the management of Specific contents} science and technology funds

Pre-supervision
(1) Supervise the budgeting to ensure the rationality and standardization of the science and technology budget signs ${ }^{[2]}$. Financial staff needs to participate in budget preparation and provide professional guidance and consultation for budget preparation.

(2) Colleges and universities with a large scale of science and technology funding should set up a special division dedicated to the finance department to administer science and technology fund management. Colleges and universities with relatively small science and technology expenditures can delegate special science and technology expenditure management tasks to the finance department, which can not only review the science and technology expenditure budget plan, but also provide them with reasonable suggestions.

During supervision

(1) In order to avoid unnecessary waste of science and technology funds and to encourage efficient use of the fund, it is necessary to supervise the standardization of reimbursements of science and technology funds, and strictly review every expenditure of science and technology funds.

(2) Through the use of information technology, the use of science and technology funds can be tracked and supervised throughout the entire process, to improve the transparency of the use of science and technology funds.

Post-supervision
The completion of a research project does not mean the end of the work of science and technology fund management and its supervision. At this time, it is necessary to conduct performance evaluation and internal audit. When carrying out performance evaluation of the project, we should not only merely evaluate the research findings, but also need to comprehensively consider the specific implementation of the budget in the entire project and the economic and social benefits generated by the project. 
Table 3. Incentive measures for scientific researchers

\begin{tabular}{ll}
\hline Incentive measures & Specific contents \\
\hline Performance evaluation & $\begin{array}{l}\text { (1) Establish a science and technology evaluation index system } \\
\text { with both financial and non-financial indicators to fully reflect } \\
\text { the various benefits of research projects, including economic } \\
\text { and social benefits. } \\
\text { (2) Incorporate the innovation, practicability, and contribution } \\
\text { of research findings to the discipline of scientific field as part of } \\
\text { the performance evaluation of research projects. } \\
\text { (3) Use the balanced scorecard model to implement } \\
\text { performance evaluation, which mainly includes the evaluation } \\
\text { in aspects such as social evaluation, social contribution, } \\
\text { research strategy, and science and technology funds. }\end{array}$ \\
$\begin{array}{l}\text { According to the actual situation in colleges and universities, } \\
\text { reasonable salary and employee benefits of research personnel } \\
\text { should be defined as reasonable salary can increase the } \\
\text { motivation of research personnel in innovation and technology. }\end{array}$ \\
\hline Salary adjustment
\end{tabular}

\section{Conclusion}

In summary, based on the policy of "streamlining administration, delegating powers, improving regulation, and strengthening services," colleges and universities must find ways of enforce the policy in the process of managing science and technology funds as well as implementing research activities throughout the process, and use information technology to build a science and technology fund management system for universities in order to facilitate the supervision of the management of science and technology funds and effectively improve the management process.

\section{Disclosure statement}

The author declares no conflict of interest.

\section{References}

[1]Di, X.H(2021). Analysis and Prevention of Corruption in the Use of Scientific Research Funds in Colleges and Universities. Research on Crime and Reform,(05): 9-17.

[2]Sun, Y.H(2021). Discussion on University Scientific Research Fund Management Based on Internal Control—Taking G University as an Example. Journal of Zhejiang Vocational College of Industry and Trade,21(01): 59-62.

[3]Qiao, M.Y(2021). Strengthening the Management and Supervision of Scientific Research Funds in Universities. Economist,(03): 96-98.

[4]Tian, Y.Y., Wang, Z.J(2021). Research on the Optimization of Scientific Research Project Funding Management Process in Colleges and Universities-Taking $\mathrm{z}$ University as an Example. Journal of Zaozhuang University,38(02): 101-108. 